Check for updates

Cite this: RSC Adv., 2018, 8, 25168

\title{
Transesterification of (hetero)aryl esters with phenols by an Earth-abundant metal catalyst $\uparrow$
}

\author{
Jianxia Chen, E. Namila, Chaolumen Bai, Menghe Baiyin, Bao Agula \\ and Yong-Sheng Bao (D) *
}

Readily available and inexpensive Earth-abundant alkali metal species are used as efficient catalysts for the transesterification of aryl or heteroaryl esters with phenols which is a challenging and underdeveloped transformation. The simple conditions and the use of heterogeneous alkali metal catalyst make this protocol very environmentally friendly and practical. This reaction fills in the missing part in transesterification reaction of phenols and provides an efficient approach to aryl esters, which are widely used in the synthetic and pharmaceutical industry.

Received 11th June 2018

Accepted 27th June 2018

DOI: $10.1039 / c 8 \mathrm{ra0} 4984 \mathrm{j}$

rsc.li/rsc-advances

Furthermore, the substrate scopes of these methods were

\section{Introduction}

Esters are important classes of chemicals that are widely found in, polymers, agrochemicals, natural products, and biological systems and they have found wide application as versatile building blocks in organic synthesis. ${ }^{1}$ Accordingly, the development of new methodologies to access these valuable molecules continues to be of great importance in synthetic organic chemistry. Transesterifications as classic organic reactions are widely applied to the preparation of esters in organic synthesis and chemical industry. ${ }^{2}$ Transesterification is a process where an ester is transformed into another through interchange of the alkoxy moiety under the catalysis of acids or bases (see Scheme 1a). However, lower reactivity of the ester carbonyl functionality and the reversible nature of the reaction equilibrium resulting in partial conversion are two major limitations associated with this class of reaction. ${ }^{3}$ In recent years, the main efforts have been devoted to developing Lewis acids, ${ }^{4}$ organic and inorganic bases $^{5}$ and N-heterocyclic carbene $(\mathrm{NHC})^{6}$ as efficient catalysts for improvement of the transesterifications of esters with alcohols. Compared with alcohols, the transesterifications of esters with phenols are more challenging due to the weaker nucleophilicity of phenols. ${ }^{7}$ Phenols are particularly attractive starting materials because most of them are readily available from fuel and biomass and the global annual production of phenols has grown to millions of tons. ${ }^{8}$ Phenols and their salt derivatives have been successfully employed as substitutes for aryl halides in many transition-metal-catalyzed transformations, ${ }^{9}$ but there are only a few reports of ester based acylation of phenols.

College of Chemistry and Environmental Science, Inner Mongolia Key Laboratory of Green Catalysis, Inner Mongolia Normal University, Hohhot, 010022, China. E-mail: sbbys197812@163.com; Tel: +86-471-4392442

$\dagger$ Electronic supplementary information (ESI) available: General information, experimental section and characterization data for the products, ${ }^{1} \mathrm{H}$ NMR, ${ }^{13} \mathrm{C}$ NMR spectra of the products. See DOI: 10.1039/c8ra04984j limited to vinyl acetates ${ }^{3}$ or specific lactones. ${ }^{7}$

Recently, aryl esters have gained significant interest as new aryl-coupling partners via nickel catalyzed C(aryl)-O cleavage (see Scheme 1b). ${ }^{10}$ Actually, the bond dissociation energy (BDE) of the $\mathrm{C}(\mathrm{acyl})-\mathrm{O}$ bond is more lower than $\mathrm{C}(\operatorname{aryl})-\mathrm{O}$ bond in aryl esters. ${ }^{10 h}$ But, catalyzed by transition-metal, there are challenges associated with C(acyl)-O bond cleavage because of decarbonylation phenomenon. ${ }^{11}$ In 2001, Yamamoto reported the first example of palladium catalyzed coupling reaction of aryl esters with organoboron compounds via $\mathrm{C}(\mathrm{acyl})-\mathrm{O}$ cleavage with carbonyl retention. However, the reaction was limited to electronically activated esters, such as perfluoroaliphatic carboxylic esters. ${ }^{12}$ Chatani reported the palladium catalyzed coupling reaction of 2-pyridyl esters with organoboron compounds. ${ }^{13}$ More recently, Newman developed an NHC-based Pd catalyst which can catalyzed Suzuki-Miyaura coupling of phenyl esters or cross-coupling between phenyl esters and aniline. ${ }^{14}$ Our

a) Traditional transestrification

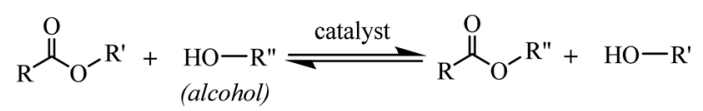

b) Transition-metal catalyzed C(Aryl)-O or C(Acyl)-O activation of Aryl ester

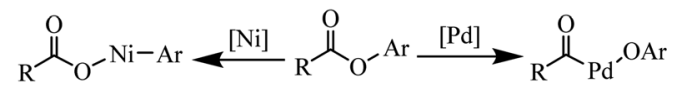

c) Alkali metal carbonate-catalysed $C(A c y l)$-O activation of Aryl ester

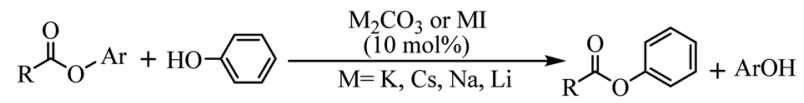

- Earth-abundant metal (K) catalyst

- Mild reaction conditions

- Heterogeneous catalyst - $>10 \mathrm{~g}$ scale, Yield up to $100 \%$

- Compatible with phenyls, pyridyl, thienyl, quinolyl and indolyl

Scheme $1 \mathrm{C}-\mathrm{O}$ bond activation of esters. 
previous work has confirmed that aryl esters can generate an activated acyl intermediate and perform an amidation reaction with tertiary amines or formamides to form amides under Pd or $\mathrm{Au}$ catalyzed conditions. ${ }^{15}$ As concluded: (1) these transformations rely on catalysts derived from rare and expensive precious metals, such as Pd, Ni and Au, which can be a significant limitation, particularly for large-scale syntheses; (2) the pyridine or benzene ring serves as a directing group for $\mathrm{C}-\mathrm{O}$ cleavage of the ester and that coordination of the nitrogen atom to the catalyst is favorable for the catalyzed reaction; (3) whether in coupling reaction via $\mathrm{C}($ aryl $)-\mathrm{O}$ activation or via $\mathrm{C}($ acyl $)-\mathrm{O}$ activation, the excess base or alkali metal halides was needed but the effect of these alkali metal salts on $\mathrm{C}-\mathrm{O}$ bond cleavage is not clear.

More presently, alkali metal salts or bases have been proven to be efficient and competitive catalysts for many reactions, such as $\mathrm{C}-\mathrm{H}$ bond silylation, ${ }^{\mathbf{1 6}}$ Heck type coupling, ${ }^{17}$ intramolecular anionic cyclization, ${ }^{18}$ hydrogenation of aromatic aldehydes, ${ }^{19}$ aminobromination, ${ }^{20}$ arylsulfonylation, ${ }^{21} \mathrm{C}-\mathrm{H}$ hydroxylation of carbonyl compound ${ }^{22}$ etc. Unlike general base catalyzed traditional reactions, only catalytic amount of alkali metal salt or base was used as catalyst in these reactions. These exciting results prompted us to reconsider the use of Earthabundant alkali metal bases or salts for the catalytic C(acyl)-O activation of aryl esters.
Herein, we disclose a mild, efficient, and general Earthabundant alkali metal species catalyzed transesterification of aryl or heteroaryl esters with phenols (relatively nonnucleophilic oxygen species) which is a challenging and under developed transformation (see Scheme 1c). The alkali metal catalyst is compatible with a range of functional groups including pyridyl, thienyl, quinolyl and indolyl, making this novel transesterification method immediately applicable to medicinal chemistry and alkaloid natural product synthesis.

\section{Results and discussion}

Our evaluation of the reaction system was initiated from the palladium catalyzed transesterification of pyridin-2-yl 2-methylbenzoate 1a with phenol 2a under air in the presence of $\mathrm{K}_{2} \mathrm{CO}_{3}$ as base at $60{ }^{\circ} \mathrm{C}$. To our delight, the expected transesterifying product phenyl 2-methylbenzoate 3aa was isolated in $99 \%$ yield (Table 1, entry 1). We were surprised to find that the transesterification reaction also took place efficiently with just a catalytic amount (10 mol\%) of $\mathrm{K}_{2} \mathrm{CO}_{3}$ and the desired product 3aa was obtained quantitatively (entry 2). The Pd, Au, Ni, Cu, Fe, $\mathrm{Ru}$, Ir and $\mathrm{Ag}$ content in the $\mathrm{K}_{2} \mathrm{CO}_{3}$ and standard reaction solution was less than $\delta=0.2 \mathrm{ppm}$ in each case (ICP-MS analysis; see the ESI $\dagger$ ), which indicated that this transesterification reaction is promoted by $\mathrm{K}_{2} \mathrm{CO}_{3}$ itself rather than catalyzed by

Table 1 Screening of different reaction parameters ${ }^{a}$

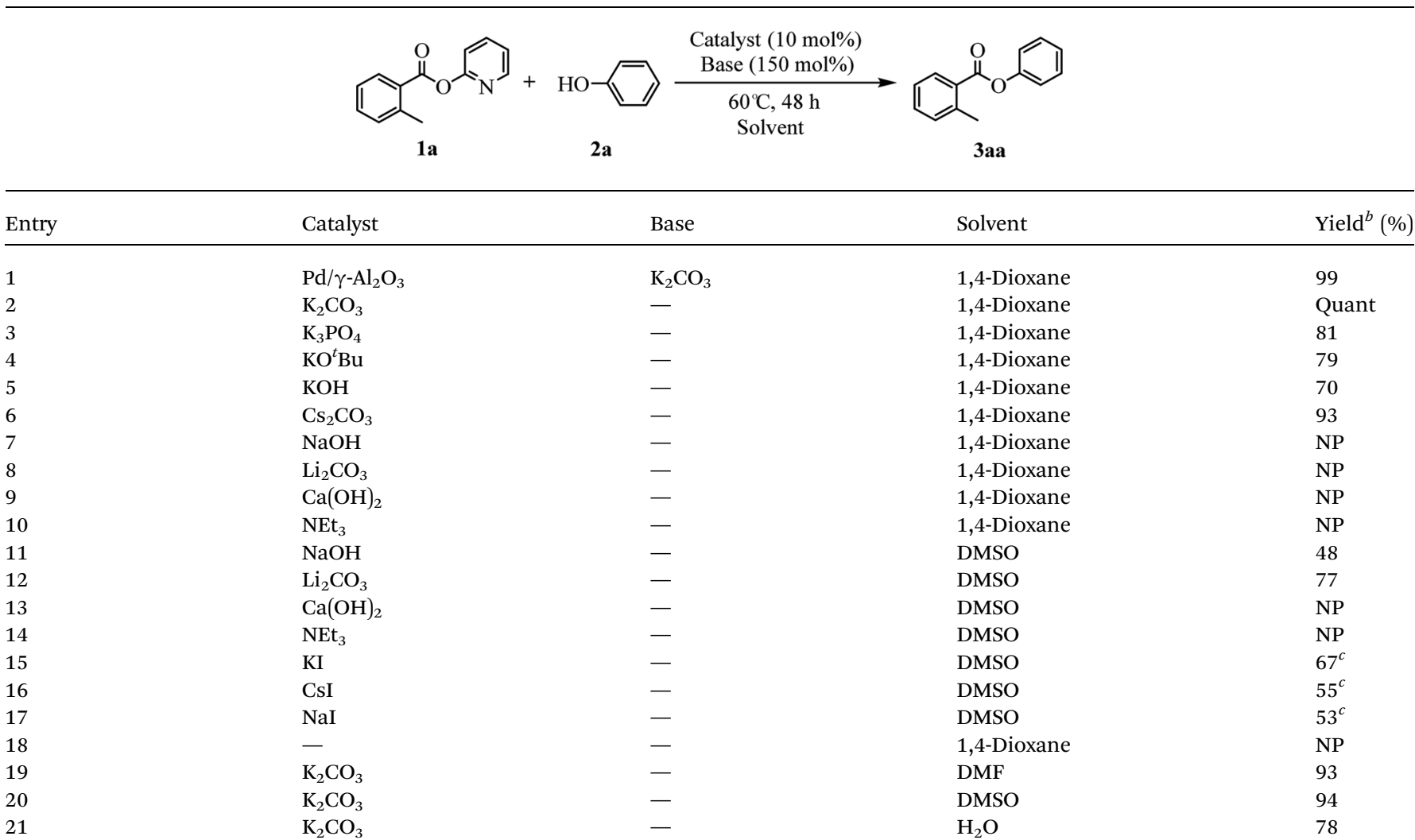

${ }^{a}$ Reaction conditions: $1 \mathrm{a}(0.1 \mathrm{mmol}), 2 \mathrm{a}(0.17 \mathrm{mmol})$, catalyst $(10 \mathrm{~mol} \%)$, solvent $(2 \mathrm{~mL}), 60{ }^{\circ} \mathrm{C}, 48 \mathrm{~h} .{ }^{b}$ Isolated yield. ${ }^{c}$ React at $120{ }^{\circ} \mathrm{C}, 24 \mathrm{~h}$. 


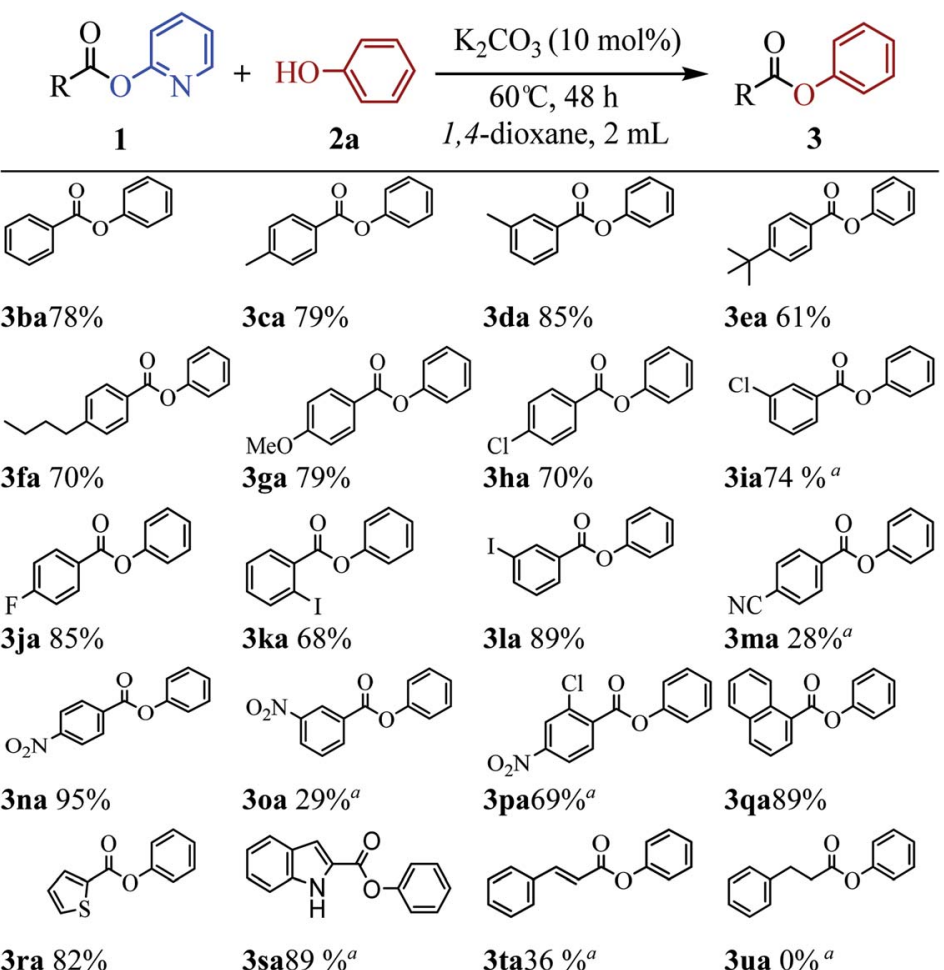

Scheme $2 \quad \mathrm{~K}_{2} \mathrm{CO}_{3}$-catalyzed transesterification of various pyridin-2-yl esters 1 with phenol $2 \mathrm{a}$. The reaction conditions $\mathrm{I}: 1$ (0.1 mmol), $2 \mathrm{a}$ ( 0.17 $\mathrm{mmol}), \mathrm{K}_{2} \mathrm{CO}_{3}(10 \mathrm{~mol} \%), 1,4$-dioxane $(2 \mathrm{~mL}), 60^{\circ} \mathrm{C}, 48 \mathrm{~h}$; yields shown are for the isolated products. ${ }^{a}$ Reaction conditions II: $\mathrm{K}_{2} \mathrm{CO}_{3}(20 \mathrm{~mol} \%)$, $120^{\circ} \mathrm{C}$.

trace metal impurities. All potassium salts and $\mathrm{Cs}_{2} \mathrm{CO}_{3}$ could catalyze the transesterification reaction smoothly (entries 2-6). As with similar many reported alkali-metal catalyzed reaction, ${ }^{16-22}$ it is becoming increasingly apparent that the identity of the base catalyst in this reaction is unusually important and extends far beyond a simple consideration of basicity. Reactions in the presence of other bases as potential catalysts, such as $\mathrm{NaOH}, \mathrm{Li}_{2} \mathrm{CO}_{3}, \mathrm{Ca}(\mathrm{OH})_{2}$ and strongly basic amines TEA, did not proceeded (entries 7-10). Aim to confirm if this transformation is solubility controlled, $\mathrm{NaOH}, \mathrm{Li}_{2} \mathrm{CO}_{3}, \mathrm{Ca}(\mathrm{OH})_{2}$ and TEA were chosen for reacting in DMSO (entries 11-14). The experiment results showed that $\mathrm{NaOH}$, and $\mathrm{Li}_{2} \mathrm{CO}_{3}$ could catalyze the transesterification reaction to give desired product in DMSO, whereas $\mathrm{Ca}(\mathrm{OH})_{2}$ and TEA could not. One could imagine that the transformation just is a base catalyzed transesterification, but non-basic alkali metal salts, including KI, CsI and NaI, could catalyze the transesterification reaction smoothly (entries 15-17). Therefore, the alkali metal ion may be involved in reaction process via $\mathrm{C}(\mathrm{acyl})-\mathrm{O}$ activation of aryl esters. Notably, a reaction in the absence of catalyst did not proceed (entry 18). The use of other solvents, such as DMF, DMSO and $\mathrm{H}_{2} \mathrm{O}$, led to the formation of 3aa in lower yields (entries 19-21). Both a decrease and increase in the reaction temperature $\left(40{ }^{\circ} \mathrm{C}\right.$ and $80{ }^{\circ} \mathrm{C}$ ) reduced the yield of $3 \mathbf{a a}$ (see the ESI $\dagger$ ).

The above results indicate that $\mathrm{K}_{2} \mathrm{CO}_{3}$ is a competent catalyst for the transesterification reaction. We next proceeded to evaluate the scope of pyridin-2-yl ester partner under the reaction conditions I (Table 1, entry 2) and found that benzoates, naphthoate, thiophene-2-carboxylate, $1 H$-indole-2-carboxylate and cinnamate readily undergo the transesterification providing phenyl esters $\mathbf{3 b a - 3 t a}$ in moderate to high yields (see Scheme 2). Benzoates with various substitution patterns at the acyl moiety were screened. The reaction proceeded smoothly not only for the benzoates bearing an electron-donating group $\left(\mathrm{Me},{ }^{n} \mathrm{Bu},{ }^{t} \mathrm{Bu}, \mathrm{OMe}\right)$ but also for those substrates having electron-withdrawing substituents $\left(\mathrm{F}, \mathrm{Cl}, \mathrm{I}, \mathrm{NO}_{2}, \mathrm{CN}\right)$ on the para-, meta- or ortho-position. Thereinto, some substrates including pyridin-2-yl 3-chlorobenzoate 1i, pyridin-2-yl 4-cyanobenzoate 1m, pyridin-2-yl 3-nitrobenzoate 10 and pyridin-2-yl 2-chloro-4-nitrobenzoate 1p, showed low activity and $20 \mathrm{~mol} \%$ of the catalyst and higher temperature (reaction conditions II) were required for reaction. The apparent electronic effect or steric effect was not founded in these benzoates. Using pyridin2-yl thiophene-2-carboxylate $\mathbf{1 r}$ as a heteroaromatic carboxylate resulted in desired phenyl thiophene-2-carboxylate 3ra in excellent yield. But hardly conditions (reaction conditions II) were required for pyridin-2-yl $1 H$-indole-2-carboxylate 1 s to furnish the products. Next, we consider if aliphatic acid ester is suitable for the transesterification reaction. The experiment results showed that saturated aliphatic acid ester, pyridin-2-yl 3phenylpropanoate $\mathbf{1} \mathbf{u}$, could not perform the transesterification reaction but unsaturated aliphatic acid ester $1 \mathrm{t}$ performed the reaction expediently albeit in comparatively lower yield under the conditions II.

The scope of the phenol partner was likewise substantial, affording products including phenyl esters 3ab-3ak, naphthyl esters 3al, 3am and quinolinyl ester 3an under the reaction conditions I (see Scheme 3). Many phenols, including 4- 

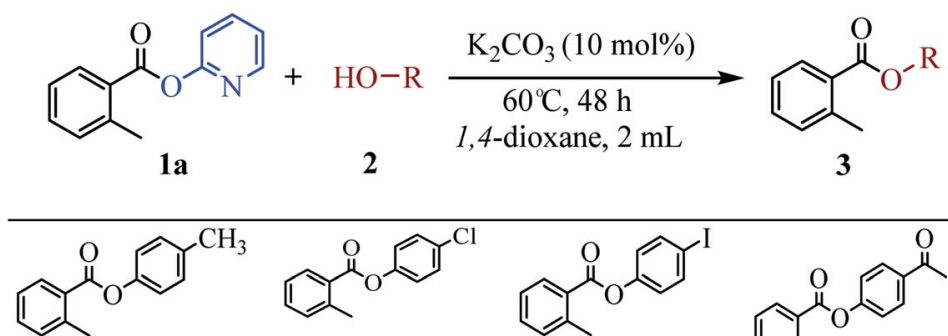

3ab quant
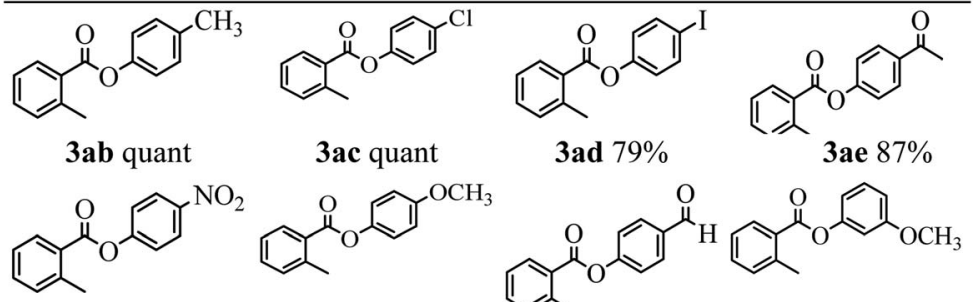

$\operatorname{3ad} 79 \%$

3af 77\%

3ag 91\%

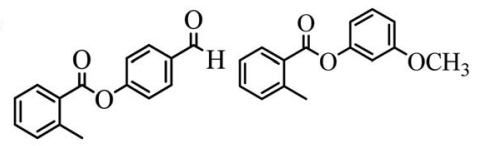<smiles>COc1cccc(OC)c1OC(=O)c1ccccc1C</smiles><smiles>Cc1ccccc1C(=O)Oc1cccc(Cl)c1Cl</smiles>

3aj $84 \%$

3ak quant

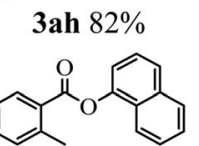

3al 93\%

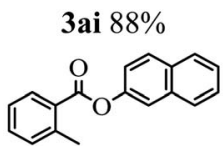

3am quant

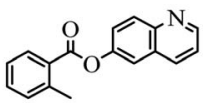

3an $88 \%$

Scheme $3 \quad \mathrm{~K}_{2} \mathrm{CO}_{3}$-catalyzed transesterification of various phenols 2 with pyridin-2-yl 2-methylbenzoate 1a. The reaction conditions I: 1 (0.1 $\mathrm{mmol}), 2 \mathrm{a}(0.17 \mathrm{mmol}), \mathrm{K}_{2} \mathrm{CO}_{3}(10 \mathrm{~mol} \%), 1,4$-dioxane $(2 \mathrm{~mL}), 60{ }^{\circ} \mathrm{C}, 48 \mathrm{~h}$; yields shown are for the isolated products.

methylphenol 2b, 4-chlorophenol 2c, 2,3-dichlorophenol 2k and naphthalen-2-ol $\mathbf{2 m}$, react with $\mathbf{1 a}$ to achieve quantitatively transesterification. Substrates containing sensitive functional groups such as 4-iodophenol $\mathbf{2 d}$ and 4-hydroxybenzaldehyde $2 \mathbf{h}$ are tolerated without any undesired side reactions. These results indicated that pyridyloxy is a good leaving group for the potassium catalyzed transesterification reaction.

To demonstrate the synthetic utility of the method, other aryl or heteroaryl esters were used instead of pyridin-2-yl esters to react with phenols. In order to verify that the ortho-directed effect of nitrogen on $\mathrm{C}(\mathrm{acyl})-\mathrm{O}$ bond cleavage of ester, pyridin-3yl 2-methylbenzoate $\mathbf{4 a}$ and pyridin-4-yl 2-methylbenzoate $\mathbf{4 b}$ were used to react with phenol $\mathbf{2 a}$ (see Table 2, entries 1 and 2). Under the condition II, desired product 3aa was isolated in the yields of $55 \%$ and $84 \%$, respectively. These results indicated there does not exist the chelating effect of nitrogen with potassium and electron-withdrawing effect (para- > meta-) of nitrogen is favorable for the $\mathrm{C}(\mathrm{acyl})-\mathrm{O}$ bond cleavage. When quinolin-6-yl benzoate $4 \mathbf{c}$ or 2-methylquinolin-4-yl benzoate $\mathbf{4 d}$ was used as substrate, the same transesterification product $\mathbf{3} \mathbf{b a}$ was isolated in the yield of $37 \%$ or $83 \%$, respectively (entries 3 and 4). The tremendous difference of yields further confirmed that electron-deficient heteroaryloxy group is easily exchanged for phenoxy group. What is more exciting is that, catalyzed by $\mathrm{K}_{2} \mathrm{CO}_{3}$, various perfluorophenyl esters $\mathbf{4 e}-\mathbf{4 j}$ performed the transesterification reaction with phenol 2a to give the desired esters in excellent yields (entries 5-10). Our experiments indicated that electron-withdrawing groups on the acyl fragment of the aryl ester $\mathbf{4 f}, \mathbf{4 g}$ are unbeneficial to this reaction (entries 6 and 7). Interestingly, starting from perfluorophenyl picolinate $\mathbf{4 k}$, which is more active in palladium catalyzed $\mathrm{C}(\mathrm{acyl})-\mathrm{O}$ activation reactions in our previous work,${ }^{15}$ the transesterification reaction was inhibited (entry 11). The presence of nitrogen in this position likely shuts down reactivity due to presumed coordination to potassium. It is believed that perfluorophenyl group is a very strong electron-withdrawing group and facilitate the $\mathrm{C}(\mathrm{acyl})-\mathrm{O}$ bond cleavage in the presence of base ${ }^{14 b}$ but when perfluorophenyl propionate $\mathbf{4} \mathbf{l}$ was used as substrate the transesterification reaction did not proceed (entry 12). This was also the case in the reaction of pyridin-2-yl 3-phenylpropanoate $\mathbf{1 u}$ (see Scheme 2, 3ua). These examples indicated that the acyl fragment of the aryl ester strongly influenced the reaction outcome and what kind of picolinate or aliphatic acid esters is not suitable for the new transesterification reaction. Further experiment confirmed that 4 -acetylphenyl benzoate $\mathbf{4 m}$ and 2,3dichlorophenyl benzoate $\mathbf{4 n}$ as well as perfluorophenyl benzoate ('activated ester') ${ }^{14 b}$ performed the transesterification reaction expediently to give the $\mathbf{3 b a}$ in moderate yields (entries 13 and 14). These results further expanded the substrates scope of new transesterification reaction to all of aryl esters. Alkyl esters, even strong electron-deficient alkyl ester-2,2,2trifluoroethyl benzoate 4o, could not react with 2a to afford desired product (entry 15). The result indicated that (hetero) aromatic ring in alkoxy part of ester $\mathbf{1}$ is necessary in the novel transesterification reaction and could control the $\mathrm{C}($ acyl)-O bond cleavage with the aid of potassium.

In order to get a better understanding about the essence of this transesterification reaction, we surveyed the reactivity of various substituted phenyl benzoates with various phenols under reaction conditions II (Table 3). Because the reactivity and stability of C(acyl)-X species can be crudely approximated by the $\mathrm{p} K_{\mathrm{a}}$ of their leaving groups, we refer to the $\mathrm{p} K_{\mathrm{a}}$ data (spectrophotometric method, $\mathrm{H}_{2} \mathrm{O}$ ) of corresponding phenols. As shown in Table 3, the electron-withdrawing effect let to lower 
Table 2 The transesterification of various aryl or heteroaryl esters with phenol $2 a^{a}$

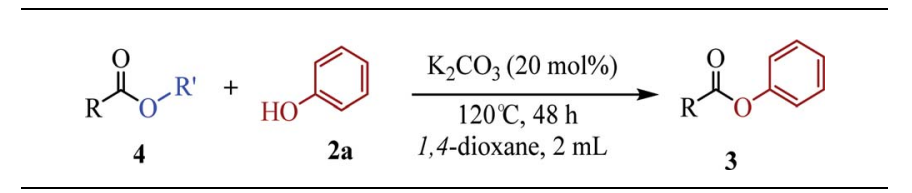

\begin{tabular}{llll}
\hline Entry & Aryl ester & Product & Yield $^{b}(\%)$ \\
\hline
\end{tabular}

1<smiles>Cc1ccccc1C(=O)Oc1cccnc1</smiles>

3aa

55

$4 a$

2<smiles>Cc1ccccc1C(=O)Oc1ccncc1</smiles>

$4 b$

3aa<smiles>O=C(Oc1ccc2ncccc2c1)c1ccccc1</smiles>

4c<smiles>Cc1cc(OC(=O)c2ccccc2)c2cc[14c](Cl)cc2n1</smiles>

3ba

83<smiles>O=C(Oc1c(F)c(F)c(F)c(F)c1F)c1ccccc1</smiles>

3ba<smiles>CCCCCCC=C[N+](=O)[O-]</smiles>

7<smiles>N#Cc1ccc(C(=O)Oc2c(F)c(F)c(F)c(F)c2F)cc1</smiles>

3ma<smiles>O=C(/C=C/c1ccccc1)Oc1c(F)c(F)c(F)c(F)c1F</smiles><smiles>O=C(Oc1c(F)c(F)c(F)c(F)c1F)c1ccccn1</smiles>

Table 2 (Contd.)

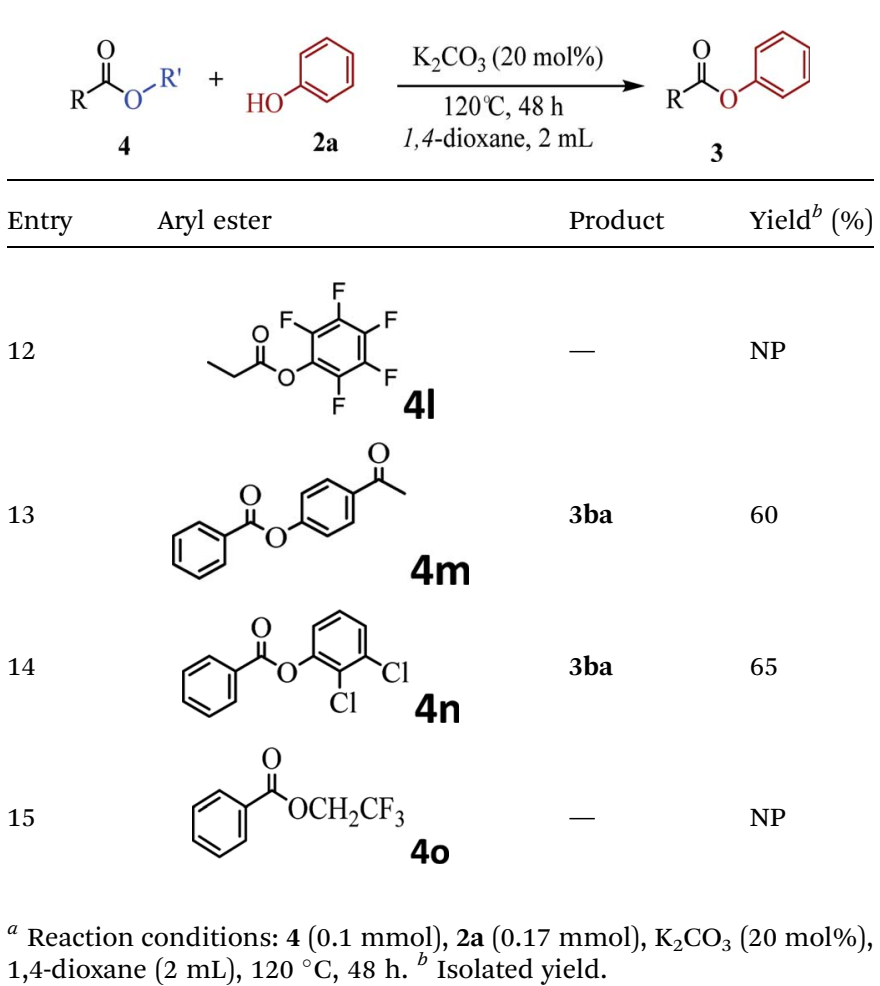

$\mathrm{p} K_{\mathrm{a}}$ value of phenols and the reactivity of esters is higher at stronger electron-withdrawing effect in the (O-Ar) fragment of the aryl esters. The 4-nitrophenyl benzoate showed the best reaction activity in the transesterification with all of phenols. Conversely, the transesterifications of other benzoates with 4nitrophenol were difficult. Although the electron-withdrawing effect of 4-nitrophenyl is lower than perfluorophenyl (perfluorophenol, $\mathrm{p} K_{\mathrm{a}}=5.49$ ), 4-nitrophenyl benzoate react with phenol to achieve quantitative transesterification. Interestingly, although naphthalen-2-ol and phenol have nearly equal $\mathrm{p} K_{\mathrm{a}}$ value, naphthalen-2-yl benzoate could also react with phenol to give the transesterification product in $89 \%$ yield, while 4 -cholorophenyl benzoate could not react with phenol. And, when naphthalen-2-yl benzoate react with 4-methoxyphenol, the yield of desired product is much higher than 4-nitrophenyl benzoate's and reach to quantitative yield. These results could not be explained by a simple nucleophilic substitution reaction process. In addition, phenoxy group of phenyl benzoate could be exchanged for 4-methoxyl phenol to give the transesterification product in $54 \%$ yield.

To investigate the practical application of this newly developed transesterification in organic synthesis, we conducted a 10 gram-scale reaction of $\mathbf{1 a}(10 \mathrm{~g})$ with $\mathbf{2 a}$ in the presence of only $10 \mathrm{~mol} \%$ of the $\mathrm{K}_{2} \mathrm{CO}_{3}$ catalyst, and isolated the desired product 3aa in $99 \%$ yield. As we can see, even though the reaction scale was magnified up to 470 times, ideal synthetically yields could be still obtained.

The core issue of alkali metal bases-catalyzed reaction mechanism is if the alkali metal ion participates in reaction process by means of coordination effect as same as transition 
Table 3 The transesterification of various substituted phenyl benzoates with various phenols ${ }^{a}$

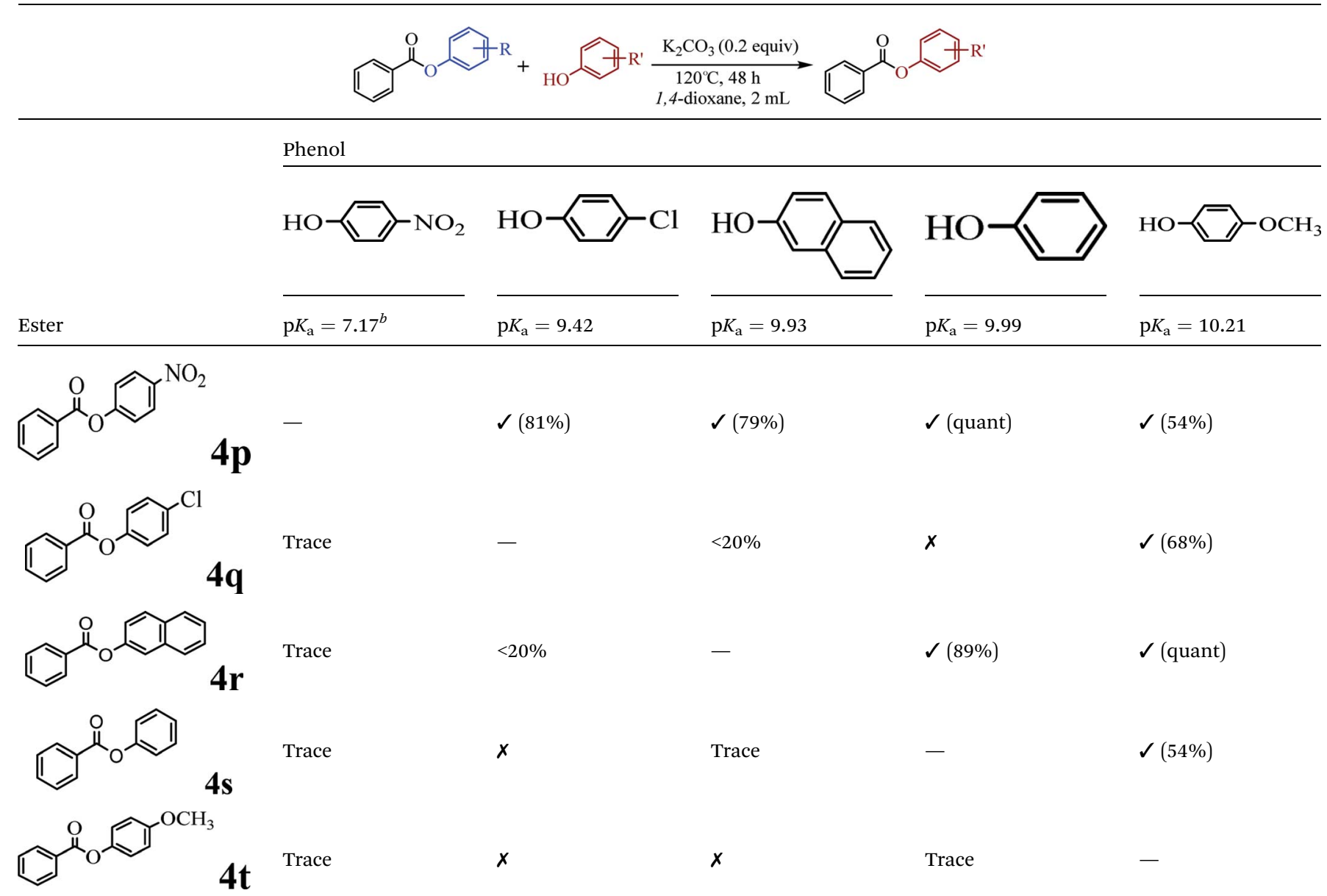

\footnotetext{
${ }^{a}$ Reaction conditions: ester $(0.1 \mathrm{mmol})$, phenol $(0.17 \mathrm{mmol}), \mathrm{K}_{2} \mathrm{CO}_{3}(20 \mathrm{~mol} \%), 1,4$-dioxane $(2 \mathrm{~mL}), 120{ }^{\circ} \mathrm{C}, 48 \mathrm{~h}$, isolated yield. ${ }^{b} \mathrm{p} K_{\mathrm{a}}$ data
} (spectrophotometric method, $\mathrm{H}_{2} \mathrm{O}$ ) was cited from Internet Bond-energy Databank (iBonD), Home Page. http://ibond.chem.tsinghua.edu.cn.

metals. Houk and coauthors suggest two plausible mechanism - one ionic involving $\mathrm{K}^{+}$and ${ }^{t} \mathrm{BuO}^{-}$ions, the other a neutral heterolytic mechanism involving the $\left[\mathrm{KO}^{t} \mathrm{Bu}\right]_{4}$ tetramer - for $\mathrm{KO}^{t} \mathrm{Bu}$ catalyzed $\mathrm{C}-\mathrm{H}$ silylation of heteroarenes, based on a combination of empirical evidence and DFT calculations. ${ }^{23}$ But the mechanistic details of the potassium carbonatecatalyzed transesterification are not well understood at this point. Nevertheless, a number of experiments were conducted to gain insight into the underlying manifolds involved (see Scheme 4). The model reaction proceeded well in the presence of 2,2,6,6-tetramethylpiperidine-1-oxyl (TEMPO) to produce the desired product 3aa in quantitative yield. This result indicated that a radical process might not be involved in the present transformation. We also studied the effect of potassium chelating agents in the transesterification reaction to investigate the importance of the cation in the catalysis. When 18crown- 6 was added to model reaction using $\mathrm{K}_{2} \mathrm{CO}_{3}$ as the catalyst, quantitative transesterification was still observed, suggesting either that ineffective chelation of the metal ion had occurred or that the cation was not necessary to the reactivity in this particular case. Furthermore, the reaction also proceeded well in argon atmosphere, which may exclude the participation of molecular oxygen in this transformation. To identify the byproduct, which was formed by the cleavage of the $\mathrm{C}-\mathrm{O}$ bond<smiles>Cc1ccccc1C(=O)OC1=N[C+]=CC=C1</smiles>

1a<smiles>Oc1ccccc1</smiles>

2a

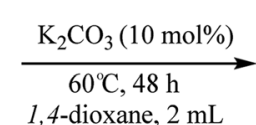

1,4-dioxane, $2 \mathrm{~mL}$

without additve: with TEMPO(100 mol\%): with 18-crown-6(10 mol\%): in Argon atmosphere:

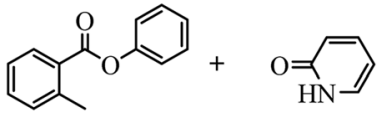

3aa (detected by GCMS)

quant

quant

quant quant

Scheme 4 Control experiments to elucidate the reaction pathways. 


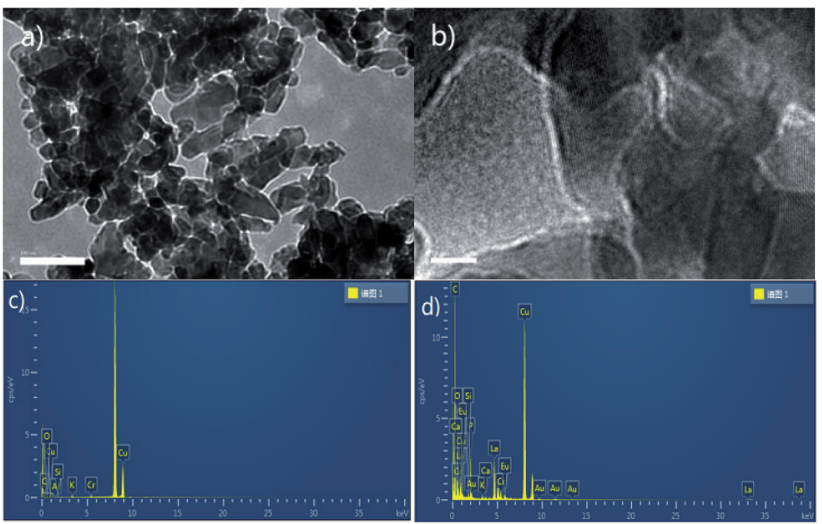

Fig. 1 (a) $200 \mathrm{~nm}$ TEM images of used catalyst; (b) $10 \mathrm{~nm}$ HRTEM images of used catalyst; ( $c$ and d) the EDS of fresh and used catalysts.

of esters, the model reaction solution was detected with GCMS after the end of the reaction (see the ESI $\dagger$ ). The GC area\% data showed that along with the desired product 3aa, a less amount of 2-pyridone was obtained, which indicated that the alkoxy group of esters eliminated to phenols in this reaction. Likewise, the GC-MS analysis of reaction of naphthalen-2-yl benzoate with phenol illustrated that naphthol was substituted by phenol in the reaction. The isolated phenols could react with carboxylic acids to synthesize esters for resource recycling.

Because $\mathrm{K}_{2} \mathrm{CO}_{3}$ dissolves in reaction solvent, we attempted to look for mechanism's evidence by means of heterogeneous approach. The filtrated used $\mathrm{K}_{2} \mathrm{CO}_{3}$ catalyst (after reaction) was studied by transmission electron microscopy (TEM), energy dispersive spectroscopy (EDS) and solid state NMR. The morphology of used $\mathrm{K}_{2} \mathrm{CO}_{3}$ catalyst was characterized by TEM.
As shown in Fig. 1a and b, used $\mathrm{K}_{2} \mathrm{CO}_{3}$ catalyst had narrow size distribution and the HRTEM images depicted clearly visible lattice fringes that evince the formation of crystalline $\mathrm{K}_{2} \mathrm{CO}_{3}$. Aim to confirm whether coordination effect between $\mathrm{K}_{2} \mathrm{CO}_{3}$ and reactants existed, the EDSs of fresh and used catalysts were compared (Fig. 1c and d). The EDS data showed there is a remarkably improvement of carbon content of catalyst after reaction. Not only that, the strong ${ }^{1} \mathrm{H}$ signals were detected in the solid state ${ }^{1} \mathrm{H}$ NMR spectra of used catalyst (see the ESI $\dagger$ ). These results indirectly proved that $\mathrm{K}_{2} \mathrm{CO}_{3}$ may be catalyzed the novel transesterification reaction via coordination effect and not just a base.

On the basis of experiments and previous reported literature, the possible mechanism and intermediates $\mathbf{I}-\mathbf{V}$ are postulated as follows (see Scheme 5). Initially, the " $\pi$-rich" two aryl (or heteroaryl) group of ester 1 interacts with $\mathrm{K}^{+}$to form a cation- $\pi$ complex I. ${ }^{23}$ It might explain why saturated aliphatic acid esters is not suitable for the new transesterification reaction. The $\mathrm{C}(\mathrm{acyl})-\mathrm{O}$ cleavage occurs through a three-centered transition state II to give the potassium intermediate III. ${ }^{14 a}$ The phenol 2 attacked the acyl carbon to form intermediate IV. Subsequently, the alkoxide attack on hydrogen cation resulted in the other phenol (byproduct), generating intermediate $\mathbf{V}$. Electron transfer of oxygen anion resulted in the desired ester 3, and regenerated $\mathrm{K}_{2} \mathrm{CO}_{3}$.

\section{Experimental}

\section{Preparation of aryl esters (1a-u; 4a-o)}

A mixture of carboxylic acid (10 mmol), 2-pyridone or phenol derivative $(10 \mathrm{mmol})$, DMAP (4-(dimethylamino)pyridine, 1

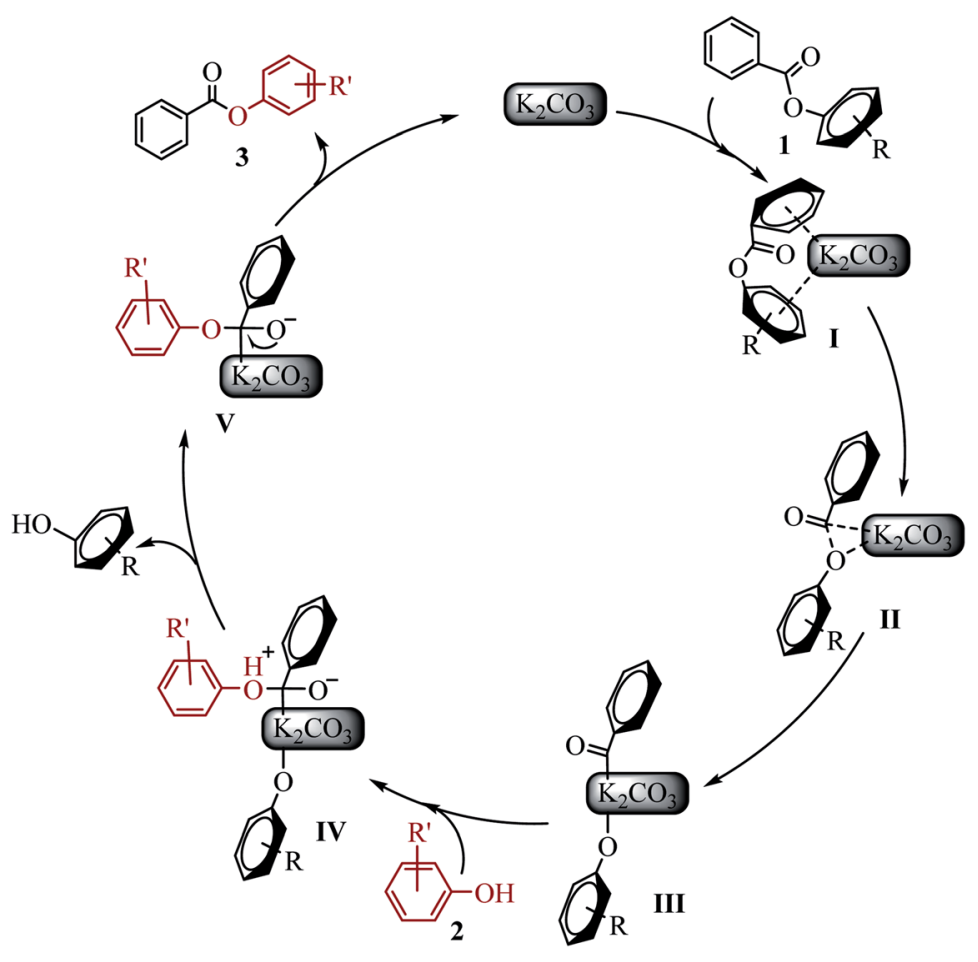

Scheme 5 Proposed preliminary mechanism. 
mmol), and 1-ethyl-3-(3-dimethylaminopropyl)carbodiamide hydrochloride (EDC $\cdot \mathrm{HCl}, 10 \mathrm{mmol})$ in THF $(50 \mathrm{~mL})$ was stirred overnight at $25{ }^{\circ} \mathrm{C}$. The resulting mixture was filtered, and the filtrate was evaporated in vacuo. The residue was purified by flash column chromatography (silica gel, ethyl ether/petroleum ether $=1: 3-1: 10$ as eluent) to afford a corresponding (hetero) aryl esters.

\section{General procedure for $\mathrm{K}_{2} \mathrm{CO}_{3}$-catalyzed transesterification}

In a typical reaction, aryl ester $(0.10 \mathrm{mmol})$, phenol $(0.17 \mathrm{mmol})$, catalyst $(0.01 \mathrm{mmol}$ or $0.02 \mathrm{mmol})$, and the solvent 1,4-dioxane $(2.0 \mathrm{~mL})$ were charged in a $25 \mathrm{~mL}$ oven dried reaction tube. Reaction was carried out $60{ }^{\circ} \mathrm{C}$ or $120{ }^{\circ} \mathrm{C}$ for $48 \mathrm{~h}$ in an oil bath under air condition. After being cooled to room temperature, the reaction solution was evaporated in vacuo. The residue was purified by flash column chromatography (silica gel, ethyl acetate/petroleum ether $=1: 5-1: 15$ as an eluent) to afford the desired product 3 . All the products were also confirmed by comparing the ${ }^{1} \mathrm{H}$ NMR and ${ }^{13} \mathrm{C}$ NMR data with authentic samples.

\section{0 gram-scale synthesis of $3 a a$}

In a 10 gram-scale reaction, pyridin-2-yl 2-methylbenzoate $\mathbf{1 a}$ (10 g, $47.0 \mathrm{mmol})$, phenol $2 \mathrm{a}(7.51 \mathrm{~g}, 79.9 \mathrm{mmol}), \mathrm{K}_{2} \mathrm{CO}_{3}(0.65 \mathrm{~g}$, $4.7 \mathrm{mmol})$, and the solvent $(150 \mathrm{~mL})$ were charged in a $250 \mathrm{~mL}$ ovendried round flask. Reaction was carried out $60{ }^{\circ} \mathrm{C}$ for $48 \mathrm{~h}$ in an oil bath under air condition. After being cooled to room temperature, the reaction solution was evaporated in vacuo. The residue was purified by flash column chromatography (silica gel, ethyl acetate/petroleum ether $=1: 5-1: 15$ as an eluent) to afford the desired product 3 aa ( $9.85 \mathrm{~g}$, 99\% yield).

\section{Conclusions}

In conclusion, we have disclosed an alkali metal catalyzed transesterification of various heteroaryl esters or aryl esters with phenols. The chemistry proceeds under mild conditions and enables the direct synthesis of a wide array of useful aryl esters, with high tunability in both the ester and phenol. In general, the pyridyloxy and electron-deficient phenoxy of the aryl esters are easily exchanged by electron-rich phenols. But some examples could not be explained by a simple nucleophilic substitution reaction process. Being insoluble in many of the solvent systems, $\mathrm{K}_{2} \mathrm{CO}_{3}$ offers the advantages of ease of recovery from the reaction medium by mere filtration and reuse of the recovered material. This methodology meets the requirement of the ideal transesterification, which is to achieve quantitative yield with the reactants in a ratio near $1: 1$ by use of mild, recyclable catalysts without requiring any technology to remove any coproduct. Detailed mechanistic studies by computational and experimental methods are underway.

\section{Conflicts of interest}

There are no conflicts to declare.

\section{Acknowledgements}

This research was financially supported by National Science Foundation of China (21462031), Program for Young Talents of Science and Technology in Universities of Inner Mongolia Autonomous Region (NJYT-17-A22).

\section{Notes and references}

1 (a) J. Otera and J. Nishikido, Esterification: Methods, Reactions, and Applications, Wiley, Hoboken, NJ, 2009, p. 1; (b) R. C. Larock, Comprehensive Organic Transformations: A Guide to Functional Group Preparations, Wiley-VCH, New York, 1999, vol. 1, pp. 1-2640; (c) J. D. Nguyen, E. M. D'Amato, J. M. Narayanam and C. R. Stephenson, Nat. Chem., 2012, 4, 854-859.

2 Some reviews on transesterifications: (a) J. Otera, Chem. Rev., 1993, 93, 1449; (b) G. A. Grasa, R. Singh and S. P. Nolan, Synthesis, 2004, 971; (c) J. Otera, Acc. Chem. Res., 2004, 37, 288.

3 (a) M. Kumar, S. Bagchi and A. Sharma, New J. Chem., 2015, 39, 8329; (b) S. Magens, M. Ertelt, A. Jatsch and B. Plietker, Org. Lett., 2008, 10, 53-56.

4 Some papers on Lewis acids as catalysts for transesterifications: (a) D. P. Sheng and I. O. Kady, Appl. Catal., A, 2009, 365, 149; (b) J. W. J. Bosco and A. K. Saikia, Chem. Commun., 2004, 1116; (c) T. Ohshima, T. Iwasaki, Y. Maegawa, A. Yoshiyama and K. Mashima, J. Am. Chem. Soc., 2008, 130, 2944; (d) A. Solhy, J. H. Clark, R. Tahir, S. Sebti and M. Larzek, Green Chem., 2006, 8, 871.

5 Some papers on organic and inorganic bases as catalysts for transesterification: (a) D. A. Watson, X. Fan and S. L. Buchwald, J. Org. Chem., 2008, 73, 7096; (b) V. Sridharan, M. Ruiz and J. C. Menéndez, Synthesis, 2010, 1053; (c) S. R. Jagtap, M. D. Bhor and B. M. Bhanage, Catal. Commun., 2008, 9, 1928.

6 Some papers on NHCs as catalysts for transesterifications: (a) G. A. Grasa, R. M. Kissling and S. P. Nolan, Org. Lett., 2002, 21, 3583; (b) G. W. Nyce, J. A. Lamboy, E. F. Connor, R. M. Waymouth and J. L. Hedrick, Org. Lett., 2002, 21, 3587; (c) T. Q. Zeng, G. H. Song and C. J. Li, Chem. Commun., 2009, 6249; (d) R. Singh, R. M. Kissling, M. A. Letellier and S. P. Nolan, J. Org. Chem., 2004, 69, 209.

7 C. Yu, H. Huang, X. Li, Y. Zhang and W. Wang, J. Am. Chem. Soc., 2016, 138, 6956-6959.

8 (a) L. Pilato, Phenolic Resins: A Century of Progress, Springer, Heidelberg, 1st edn, 2010; (b) M. Granda, C. Blanco, P. Alvarez, J. Patrick and R. Merendez, Chem. Rev., 2014, 114, 1608.

9 (a) D. G. Yu, B. J. Li, S. F. Zheng, B. T. Guan, B. Q. Wang and Z. J. Shi, Angew. Chem., Int. Ed., 2010, 49, 4566; (b) Z. Chen, H. Zeng, S. A. Girard, F. Wang, N. Chen and C. J. Li, Angew. Chem., Int. Ed., 2015, 54, 14487; (c) H. Zeng, Z. Qiu, A. Dom\&nguez-Huerta, Z. Hearne, Z. Chen and C. J. Li, ACS Catal., 2017, 7, 510.

10 (a) H. Xu, K. Muto, J. Yamaguchi, C. Zhao, K. Itami and D. G. Musaev, J. Am. Chem. Soc., 2014, 136, 14834-14844; 
(b) L. Xu, B. J. Li, Z. H. Wu, X. Y. Lu, B. T. Guan, B. Q. Wang, K. Q. Zhao and Z. J. Shi, Org. Lett., 2010, 12, 4; (c) K. W. Quasdorf, X. Tian and N. K. Garg, J. Am. Chem. Soc., 2008, 130, 14422-14423; (d) C. Zarate and R. Martin, J. Am. Chem. Soc., 2014, 136, 2236-2239; (e) R. Takise, K. Muto, J. Yamaguchi and K. Itami, Angew. Chem., Int. Ed., 2014, 53, 6791-6794; (f) J. Cornella, E. P. Jackson and R. Martin, Angew. Chem., Int. Ed., 2015, 54, 4075-4078; (g) M. Tobisu and N. Chatani, Top. Curr. Chem., 2016, 374, 41; (h) J. Yang, T. Chen and H. B. Han, J. Am. Chem. Soc., 2015, 137, 1782-1785; (i) Y. Gu and R. Martín, Angew. Chem., Int. Ed., 2017, 56, 3187; (j) L. Guo, C. C. Hsiao, H. Yue, X. Liu and M. Rueping, ACS Catal., 2016, 6, 4438-4442.

11 (a) W. I. Dzik, P. P. Lange and L. J. Gooßen, Chem. Sci., 2012, 3, 2671-2678; (b) K. Amaike, K. Muto, J. Yamaguchi and K. Itami, J. Am. Chem. Soc., 2012, 134, 13573-13576; (c) K. Muto, J. Yamaguchi, D. G. Musaev and K. Itami, Nat. Commun., 2015, 6, 7508; (d) L. Guo, A. Chatupheeraphat and M. Rueping, Angew. Chem., Int. Ed., 2016, 55, 1181011813; (e) H. F. Yue, L. Guo, S. C. Lee, X. Q. Liu and M. Rueping, Angew. Chem., Int. Ed., 2017, 56, 3972-3976; (f) X. H. Pu, J. F. Hu, Y. Zhao and Z. Z. Shi, ACS Catal., 2016, 6, 6692-6698; (g) Q. Q. Lu, H. Yu and Y. Fu, J. Am. Chem. Soc., 2014, 136, 8252-8260.

12 R. Kakino, I. Shimizu and A. Yamamoto, Bull. Chem. Soc. Jpn., 2001, 74, 371-376.

13 H. Tatamidani, F. Kakiuchi and N. Chatani, Org. Lett., 2004, 6, 3597-3599.

14 (a) T. B. Halima, W. Zhang, I. Yalaoui, X. Hong, Y. Yang, K. N. Houk and S. G. Newman, J. Am. Chem. Soc., 2017,
139, 1311-1318; (b) T. B. Halima, J. K. Vandavasi, M. Shkoor and S. G. Newman, ACS Catal., 2017, 7, 21762180.

15 (a) Y. S. Bao, M. Baiyin, B. Agula, M. L. Jia and Z. Bao, J. Org. Chem., 2014, 79, 6715; (b) Y. S. Bao, Z. Bao, B. Agula, M. Baiyin and M. L. Jia, J. Org. Chem., 2014, 79, 803; (c) Y. S. Bao, L. Wang, M. Jia, A. Xu, B. Agula, M. Baiyin and Z. Bao, Green Chem., 2016, 18, 3808-3814.

16 (a) A. A. Toutov, W. B. Liu, K. N. Betz, A. Fedorov, B. M. Stoltz and R. H. Grubbs, Nature, 2015, 518, 80-84; (b) A. A. Toutov, K. N. Betz, D. P. Schuman, W. B. Liu, A. Fedorov, B. M. Stoltz and R. H. Grubbs, J. Am. Chem. Soc., 2017, 139, 1668-1674; (c) V. Leich, T. P. Spaniol and J. Okuda, Organometallics, 2016, 35, 1179-1182.

17 A. L. Rodriguez, T. Bunlaksananusorn and P. Knochel, Org. Lett., 2000, 2, 3285-3287.

18 R. Gai, D. F. Back and G. Zeni, J. Org. Chem., 2015, 80, 1027810287.

19 R. Radhakrishan, D. M. Do, S. Jaenicke, Y. Sasson and G. K. Chuah, ACS Catal., 2011, 1, 1631-1636.

20 Z. G. Chen, Y. Wang, J. F. Wei, P. F. Zhao and X. Y. Shi, J. Org. Chem., 2010, 75, 2085-2088.

21 X. Li, X. Xu, P. Hu, X. Xiao and C. Zhou, J. Org. Chem., 2013, 78, 7343-7348.

22 Y. F. Liang and N. Jiao, Angew. Chem., 2014, 126, 558-562. 23 S. Banerjee, Y. Yang, I. D. Jenkins, Y. Liang, A. A. Toutov, W. Liu, D. P. Schuman, R. H. Grubbs, B. M. Stoltz, E. H. Krenske, K. N. Houk and R. N. Zare, J. Am. Chem. Soc., 2017, 139, 6880-6887. 